\title{
Microsatellite design for species delimitation and insights into ploidy for the Lake Baikal Cladophoraceae species flock
}

\author{
Sergio Díaz Martínez (1) ${ }^{1,2}$, Christian Boedeker (1) ${ }^{1}$, and Giuseppe C. Zuccarello (i) ${ }^{1}$ \\ ${ }^{1}$ School of Biological Sciences, Victoria University of Wellington, PO Box 600, Wellington 6140, New Zealand \\ ${ }^{2}$ Herbario FEZA, Facultad de Estudios Superiores Zaragoza, UNAM, Batalla de 5 de mayo S/N Col. Ejército de Oriente, Ciudad de México C.P. 09230, \\ Mexico
}

\begin{abstract}
Ancient lakes are centres of adaptive radiation and speciation. The Cladophoraceae endemic to ancient Lake Baikal is a morphologically diverse group nested within Rhizoclonium that may represent a case of sympatric speciation. Recent research using ribosomal DNA markers indicates that these taxa form a monophyletic group but was not able to resolve boundaries between all of the investigated morphospecies due to very low genetic diversity. For this reason, a population genetics approach using more variable markers was investigated. In this study, we developed a set of microsatellites (SSRs) using high-throughput sequencing (HTS) data obtained from three morphospecies of Cladophoraceae from Lake Baikal. To increase amplification rate of the microsatellites across taxa, we performed an in silico cross-validation step comparing the microsatellites retrieved from three HTS datasets and tested the most promising loci on 14 of the mostly endemic morphospecies. We obtained 11 SSRs that cross-amplified among morphospecies, eight SSRs in 12 taxa and three in only four taxa. Our results showed that most loci had more than two alleles, but also displayed variation between and within morphospecies. These results indicate that this group may have gone through polyploidisation. Polyploid systems require a different approach from standard population genetic analyses. We produced 'allelic phenotypes' (presence/absence matrices) to analyse genetic diversity. We showed that similarity indices mostly grouped morphospecies, suggesting that this scoring method will be useful in species delimitation, but further work is needed to elucidate the speciation process in this algal species flock in Lake Baikal.
\end{abstract}

ARTICLE HISTORY

Received 04 October 2019

Accepted 15 May 2020

Published online 30 June

2020

KEYWORDS

Ancient lakes; Chlorophyta; HTS; Polyploidy; SSRs

\section{INTRODUCTION}

Ancient lakes are centres of great diversity which can be viewed as natural evolutionary laboratories containing examples of ecological diversification, speciation, and adaptive radiations (Cristescu et al. 2010; Wilke et al. 2008). Lake Baikal in south-eastern Siberia, Russia, is more than 25 million years old and the oldest lake in the world (Mats 1993). The diversity of the lake is extraordinarily high with more than half of the animal species being endemic and considered examples of adaptive radiations (e.g. Schön \& Martens 2012; Sherbakov 1999; Yokoyama \& Goto 2005). However, studies on the ecology, evolution, and speciation of the algal flora are limited (for example, see Boedeker et al. 2018; Kulikovskiy et al. 2012; Volkova et al. 2018).

Among the algae of Lake Baikal, the family Cladophoraceae is highly represented (Boedeker et al. 2018; Izhboldina 2007). The family Cladophoraceae is a cosmopolitan group of algae that can be found in fresh, brackish, and marine waters. The life cycle is generally haplo - diplontic and isomorphic, but asexual reproduction occurs in several species (Škaloud et al. 2018). Thalli are filamentous, containing multiple nuclei and chloroplasts per cell, and have relatively simple morphologies consisting of uniseriate branched or unbranched filaments (Škaloud et al. 2018; Van den
Hoek et al. 1995). The morphological simplicity of the species within the order, phenotypic plasticity in many species, and convergent evolution of characters have created confusion in the taxonomy and classification of this group. During the last decades, molecular markers have solved many of the taxonomic problems as well as helping in species delimitation (i.e. Boedeker et al. 2012, 2016; Hanyuda et al. 2002; Zhu et al. 2018).

The traditional taxonomy of the endemic Baikalian Cladophoraceae is based on morphology (Izhboldina 2007) and reflects their wide morphological diversity with 16 distinct taxa (14 species and 2 varieties) placed in four genera: Chaetocladiella C.Meyer \& A.P.Skabichevsky, which branches only near its holdfast; the unbranched Chaetomorpha Kützing (=Ch.); the abundantly branched Cladophora Kützing $(=C l$.$) ;$ and the diminutive Gemmiphora Skabichevsky $(=G$.) (Boedeker et al. 2018; Izhboldina 2007). However, recent molecular studies (Boedeker et al. 2018) using nuclear ribosomal markers (SSU, LSU, and ITS) revealed that the endemic Baikalian Cladophoraceae are actually a monophyletic group with low genetic differentiation having a maximum of $2.8 \%$ pairwise differences in the ITS region (Boedeker et al. 2018). These phylogenies also showed that this clade is nested within Rhizoclonium Kützing, a genus which shows little 
morphological differentiation (simple unbranched or sparsely branched filaments), but high genetic diversity (Boedeker et al. 2018). The phylogenetic signal of the ribosomal markers differentiated the Baikalian Cladophorales into two major clades (A and B; Table S1), but lacked support for many other clades and showed little or no genetic difference between some morphospecies.

These results suggest that this group fulfils many of the criteria of a species flock such as monophyly, endemism, and high morphological diversity (Greenwood 1984), but also questions whether the morphospecies are reproductively isolated and whether this group represents a case of sympatric speciation. To address these questions, a population genetics approach using more variable markers is needed. Among the markers available for population genetics, microsatellites have been considered a good option to assess genetic diversity and population structure of animals, plants, and algae (Selkoe \& Toonen 2006). Microsatellites, also referred to as simple sequence repeats (SSRs), consist of repeated motifs of two to six nucleotides that occur in all eukaryotic genomes. Although other genetic markers are used in population genetics (e.g. amplified fragment length polymorphisms, random amplified polymorphic DNAs, inter simple sequence repeats, and single nucleotide polymorphisms), SSRs have several advantages that make them ideal for studying population genetics. These include co-dominance (enabling differentiation of homozygotes and heterozygotes), putative neutrality, and high levels of polymorphism. In addition, they can be applied to small and preserved tissues (Guichoux et al. 2011; Selkoe \& Toonen 2006). Furthermore, technologies of high-throughput sequencing (HTS) and high computational power provide an easy way to obtain many potential SSRs for low cost and short development time while exploring large portions of an organism's genome (Gardner et al. 2011; Schoebel et al. 2013).

The number of studies using SSRs in algae has increased over the last years, showing their reliability to assess many questions, such as identification of individuals belonging to a particular population (Henrichs et al. 2013; Krueger-Hadfield et al. 2017); assessment of population structure (Kostamo et al. 2012; Krueger-Hadfield et al. 2011; Sjøtun et al. 2017); analysis of hybridisation (Montecinos et al. 2017; Zardi et al. 2011); and life cycle dynamics (Couceiro et al. 2015; Guillemin et al. 2008; Krueger-Hadfield et al. 2016). However, only a few studies have used SSRs in Cladophorales. These investigations involve population structure of Cladophoropsis membranacea (Hofman Bang ex C.Agardh) Børgesen (Van der Strate et al. 2000, 2002a, 2002b, 2003) and revealed fine-scale structure, and even possible cryptic species at larger scales.

One of the main difficulties in the study of population genetics in algae is the occurrence of isomorphic haplodiplontic life cycles (Valero et al. 2001). In some cases, it is possible to overcome this by distinguishing reproductive structures, measuring nuclear DNA content, using chemical tests, or counting the number of alleles in each locus (Couceiro et al. 2015; Engel et al. 2004; Guillemin et al. 2008; Krueger-Hadfield et al. 2011; Van der Strate et al. 2002b). Species of Cladophorales have a mostly isomorphic alternation of generations (van den et al. 1995) and reproductive structures are similar between sporophytic and gametophytic phases, making it impossible to distinguish morphologically between haploids and diploids. Another potential challenge is the occurrence of polyploidy which has been frequently reported (Boedeker et al. 2012; Hinson \& Kapraun 1991; Kapraun 2007), making it even more difficult to determine the actual ploidy level of individuals. Little is known about the effects of polyploidization in algae, although it is generally assumed that it modifies the life cycle and expression of morphology (i.e. Kapraun 2007; Kapraun et al. 2007; Parodi \& Cáceres 1991; Wik-sjöstedt 1970). Most of the studies on Cladophoraceae are based on Cladophora glomerata (Linnaeus) Kützing, where it is hypothesised that polyploidy has modified its life cycle leading to obligate asexual reproduction, and aided the transition from marine to fresh water (see Graham 1982). It has also been suggested that polyploidy is involved in the great morphological variation in Cladophora species (Wik-sjöstedt 1970). Another study on Cladophora suggested that populations of different ploidy levels may show differences in the number of apical ramifications, although other characteristics, such as cell size, remain highly similar (Parodi \& Cáceres 1991).

The aim of this is study was to design a set of microsatellite markers that cross-amplifies across the species flock of Cladophoraceae of Lake Baikal. SSRs were developed using HTS data of three morphospecies. We calculated statistics and similarity clusters to provide a preliminary overview of their utility in providing diversity and genetic signals to address evolutionary questions of this group (e.g. species boundaries and population structure)

\section{MATERIAL AND METHODS}

\section{HTS data and assembly}

Total DNA was extracted from samples of three morphospecies: Cl. kursanovii Skabitschevsky, Ch. baicalensis K.I.Meyer and Ch. moniliformis Skabitschevsky from Lake Baikal collected during September 2014 (collection numbers 475, 50, and 515, respectively). Many individuals from the same locality were combined to obtain sufficient DNA for HTS. These species were selected based on ease in identification based on morphology, with each morphospecies likely to belong to a genetically distinct lineage, and include species of both clades A and B from Boedeker et al. (2018). DNA extractions were done using a CTAB lysis protocol (Zuccarello \& Lokhorst 2005). A minimum of $50 \mathrm{ng}$ of DNA was sequenced (Novogene, Beijing, China) following the protocols suggested by the company. The respective genetic libraries for HTS were created by digesting the genomic DNA with the restriction enzyme EcoRI, ligation of fragments with adapters, fragment recovery (200 400 bp and $400 \sim 600 \mathrm{bp})$ and sequenced in an Illumina HiSeq PE250 sequencer. The resulting reads were cleaned by removing adapters and low-quality reads (Phred score $<$ Q20). Finally, the reads of the three morphospecies were assembled independently using Velvet 1.2.07 (Zerbino \& Birney 2008) and Velvetopt 2.2.5 with 
the parameters starting with $k$-mers of 23 to 31 base pairs with subsequent increments of three base pairs per $k$-mer $(-\mathrm{s} 23$ - e $31-\mathrm{x} 3)$.

\section{Microsatellite detection and primer development}

The first search for SSRs was done using all assembled sequences. We used MSATCOMMANDER (Faircloth 2008) to create a list of potential SSRs including their sequence, microsatellite motif type, and the respective forward and reverse primers. This helped us to determine the frequency and motif types of SSRs in the genomes.

To increase the probability of amplifying the same loci between morphospecies of Baikalian Cladophoraceae, we performed a cross-validation protocol in silico using the sequences from the three samples. All the sequences listed by MSATCOMMANDER as containing a microsatellite region were imported into Geneious R8.1 (www.geneious. com; Kearse et al. 2012) and assembled using the de novo option at High Sensitivity/Medium. All contigs were examined by looking for those containing the same sequences in at least two of the three datasets/morphospecies. Contigs of less than 100 bp were discarded. New primers were designed using Primer3 2.3.7 plug-in (Rozen \& Skaletsky 2000) favouring conserved flanking regions.

\section{Microsatellite testing}

A total of 44 samples from 14 endemic morphospecies of Baikalian Cladophoraceae plus several ambiguously identified individuals and two Rhizoclonium sp. samples were tested (Table S1). The samples were collected from different localities around Lake Baikal (Fig. S1, Table S2). DNA was extracted using a Chelex method (Goff \& Moon 1993). For specimens forming entangled mats, each individual was examined using a stereoscope, and parts of the thallus arising from the same basal portion were used. For unbranched filamentous forms, only a single filament was used.

The primers were tested in two steps: first to check if the primers produced fragments of expected size, and second, to check if the loci were polymorphic. First, a standard PCR was conducted using the protocol: $94{ }^{\circ} \mathrm{C}$ for $4 \mathrm{~min}$ for initial denaturation, followed by 30 cycles of $1 \mathrm{~min}$ at $94^{\circ} \mathrm{C}, 1 \mathrm{~min}$ at $56^{\circ} \mathrm{C}$ and $1 \mathrm{~min}$ at $72{ }^{\circ} \mathrm{C}$, and a final extension at $72{ }^{\circ} \mathrm{C}$ for $10 \mathrm{~min}$. The PCR mix had a volume of $20 \mu \mathrm{l}$ and consisted of $1 \mu \mathrm{l}$ of diluted genomic DNA (1:10), $200 \mu \mathrm{M}$ of each dNTP, $0.4 \mu \mathrm{M}$ of each primer, $1.5 \mathrm{mM}$ of $\mathrm{MgCl}_{2}, 0.05 \% \mathrm{BSA}, 1 \mathrm{X}$ reaction buffer, and 0.7 units of BIOTAQ Taq polymerase (Bioline, London, UK). The PCR products were electrophoresed in $1.5 \%$ agarose, and post-stained with ethidium bromide to check for products.

All primers that produced amplicons were used for the next step to check fragment read quality. A three primer method for fluorescently labelling fragments (Schuelke 2000) was used for almost all the primer combinations, except for loci $5 \mathrm{a}$ and 6 . The method consists of the addition of a third primer with the M13 (5'-TGT AAA ACG ACG GCCAGT-3') sequence ligated on its $5^{\prime}$ end to one of the four fluorescent dyes (6FAM, PET, VIC, or NED), and a modified microsatellite forward primer with an M13 tail at its 5' end. A two-cycle PCR program used consisted of $94{ }^{\circ} \mathrm{C}$ for $4 \mathrm{~min}$ for initial denaturation, followed by 25 cycles of $30 \mathrm{sec}$ at $94{ }^{\circ} \mathrm{C}, 30 \mathrm{sec}$ at $56{ }^{\circ} \mathrm{C}$, and $120 \mathrm{sec}$ at $65^{\circ} \mathrm{C}$ for extension; followed by 8 cycles at $94^{\circ} \mathrm{C}$ for $30 \mathrm{sec}, 30 \mathrm{sec}$ at $53{ }^{\circ} \mathrm{C}$, and $120 \mathrm{sec}$ at $65{ }^{\circ} \mathrm{C}$ for extension, followed by a final extension at $65^{\circ} \mathrm{C}$ for $15 \mathrm{~min}$. The extension temperature was modified to reduce the occurrence of stutters (Seo et al. 2014). The PCR mix had a volume of $15 \mu \mathrm{l}$ and consisted of $1 \mu \mathrm{l}$ of diluted genomic DNA, $200 \mu \mathrm{M}$ of each dNTP, $0.4 \mu \mathrm{M}$ of each M13 labelled and reverse primers, $0.1 \mu \mathrm{M}$ of forward primer, $1.5 \mathrm{mM}$ of $\mathrm{MgCl}_{2}, 0.05 \% \mathrm{BSA}, 1 \mathrm{X}$ reaction buffer, and 0.7 units of Taq polymerase. For loci $5 \mathrm{a}$ and 6, the forward primers were directly labelled with FAM and PET, respectively. A standard PCR program and mix concentrations were followed. We performed repeated PCRs on random samples using DNA polymerase with proofreading exonuclease activity (RANGER DNA Polymerase, Bioline, London, UK), which has an increased fidelity, to compare and confirm the chromatogram profiles of the selected loci (i.e. 5a and 6), and check if noticeable differences occurred between repeats and polymerases.

The labelled PCR products were combined with up to four different loci per vial ('poolplexed') and analysed commercially (Macrogen Inc., Seoul, Korea) on an ABI3730XL Genetic Analyser (Life Technologies Corp.) with GeneScan 500 LIZ as a size standard. The resulting chromatograms were analysed and scored in GeneMarker 2.0.2 (SoftGenetics, LLC, State College, Pennsylvania, USA) using the default parameters for SSRs. Each chromatogram was reviewed manually and compared with chromatograms of the same and different morphospecies, looking for repeated profiles and identical fragment sizes to assign and correct the alleles. In difficult profiles showing stutters the allele scoring followed the method of the manual routine of Pfeiffer et al. (2011) with slight modifications. This approach is considered reliable over automated scoring to reduce noise in difficult loci due to polyploidy (Bhandawat et al. 2016; Cărăbuș et al. 2015; Könyves et al. 2016; Pfeiffer et al. 2011). Therefore, depending on their putative quality, the peaks in the chromatograms were considered as alleles. For this study, the highest main peaks were coded as alleles and peaks directly before or after the main peak with no less than $85 \%$ of the height of the main peak were considered as different alleles. An increase of intensity after a putative allele was coded as a different allele, as it is assumed that the intensity of stutters decreases after the 'true' allele, and stutter bands tend to occur before the 'real' peaks. Peaks with different intensities but far enough to be discarded as stutter were coded as allele if the peak was present in other profiles. Context information, such as morphospecies and locality, was also considered, for example, alleles that were found multiple times in the same morphospecies or location. The occurrence of chromatograms showing identical peaks and profiles in different samples was also used to corroborate the allele scoring.

All alleles were scored as 'allelic phenotypes'. This method consists of coding each allele independently in a presence/ absence matrix, similar to DNA fingerprints (Andreakis et al. 2009; Besnard et al. 2008; Dufresne et al. 2014; García-Verdugo et al. 2013; Pfeiffer et al. 2011). For each locus, total number of 
Table 1. Number and proportion of SSRs obtained in the three HTS datasets. Group designation follows Boedeker et al. (2018)

\begin{tabular}{llll}
\hline & \multicolumn{3}{c}{ No. of SSRs } \\
\cline { 2 - 4 } Motif repeat & $\begin{array}{c}\text { Chaetomorpha baicalensis } \\
\text { (Group B) }\end{array}$ & $\begin{array}{c}\text { Chaetomorpha } \\
\text { moniliformis } \\
\text { (Group A) }\end{array}$ & $\begin{array}{c}\text { Cladophora } \\
\text { kursanovii } \\
\text { (Group A) }\end{array}$ \\
\hline 2 & 131 & 392 & 265 \\
\hline 3 & 1735 & 3859 & 3367 \\
4 & 49 & 168 & 406 \\
5 & 21 & 85 & 191 \\
6 & 14 & 20 & 21 \\
Total & 1950 & 4524 & 4250 \\
\hline
\end{tabular}

alleles, and maximum and minimum number of alleles per individual were calculated, as well as the number of distinct multi-locus genotypes. Other genetic diversity statistics at the morphospecies level were calculated in GenAlEx 6.5 (Peakall \& Smouse 2012) such as the number of alleles, the mean value of unbiased diversity $(u h)$, and the number of private alleles $(\mathrm{Pa})$. Allelic phenotypes of all loci were combined in a single matrix. The information contained in the SSR markers was explored by creating a UPGMA tree considering all genotypes independently and using a Jaccard similarity index in NTSYSpc 2.1 (Applied Biostatistics, Inc.).

\section{RESULTS}

\section{HTS data}

The HTS retrieved more than 16 million reads in each of the three samples. Other genomic features are reported in Table S3. The total cleaned reads amounted to 10.75 gigabases $(\mathrm{Gb})$ in $\mathrm{Ch}$. baicalensis, $10.1 \mathrm{~Gb}$ in C. moniliformis, and $9.35 \mathrm{~Gb}$ in $\mathrm{Cl}$. kursanovii. The total numbers of contigs obtained after assembly were considerably different between species: 135,578 in $\mathrm{Ch}$. baicalensis, 318,757 in Ch. moniliformis, and 105,464 in Cl. kursanovii. Microsatellite number differed between species and appeared to have no relation to the number of contigs generated. In Ch. baicalensis, we found 1950 SSRs, in Ch. moniliformis 4524, and in Cl. kursanovii 4250. Three base pair repeat motifs were dominant in all species, followed by dinucleotide repeats (Table 1).

\section{Microsatellite cross-amplification}

After filtering dubious and short assemblies, 52 SSRs were cross-validated in at least two datasets. To complement the potential markers, another 24 SSRs present only in one dataset were selected, making a final SSRs list of 76 potential markers. From the total potential markers, 38 SSRs amplified in all morphospecies, 18 amplified only in morphospecies from group $\mathrm{A}$, and 20 SSRs did not produce amplicons.

From the total of 56 SSRs ( 38 that amplified in all samples and 18 only in group A), 22 SSRs produced unusable chromatograms and 23 SSRs were not polymorphic. The remaining 11 SSRs (Table 2) showed variation and were used with all 44 individuals exploring their variability and characteristics. Three of these loci are markers that amplified only in morphospecies of group A (Table 2). Unfortunately, the samples of Chaetocladiella (= C.) pumila (K.I.Meyer) K.I.Meyer \& Skabitschevsky and C. litoralis (Skabichevsky) Meyer \& Skabichevsky did not produce good amplicons and were not included in subsequent analyses. Although primers were successful in most samples, some individuals did not produce amplicons at loci 14 (4 individuals), 34 (20 individuals), and 515-35 (6 individuals). These loci were not discarded as they appeared to be informative for other morphospecies, particularly those from group A.

Table 2. Primer sequence and characteristics of the selected 11 SSRs markers. The ability to cross-amplify in all species in clade A (Boedecker et al. 2018) is shown.

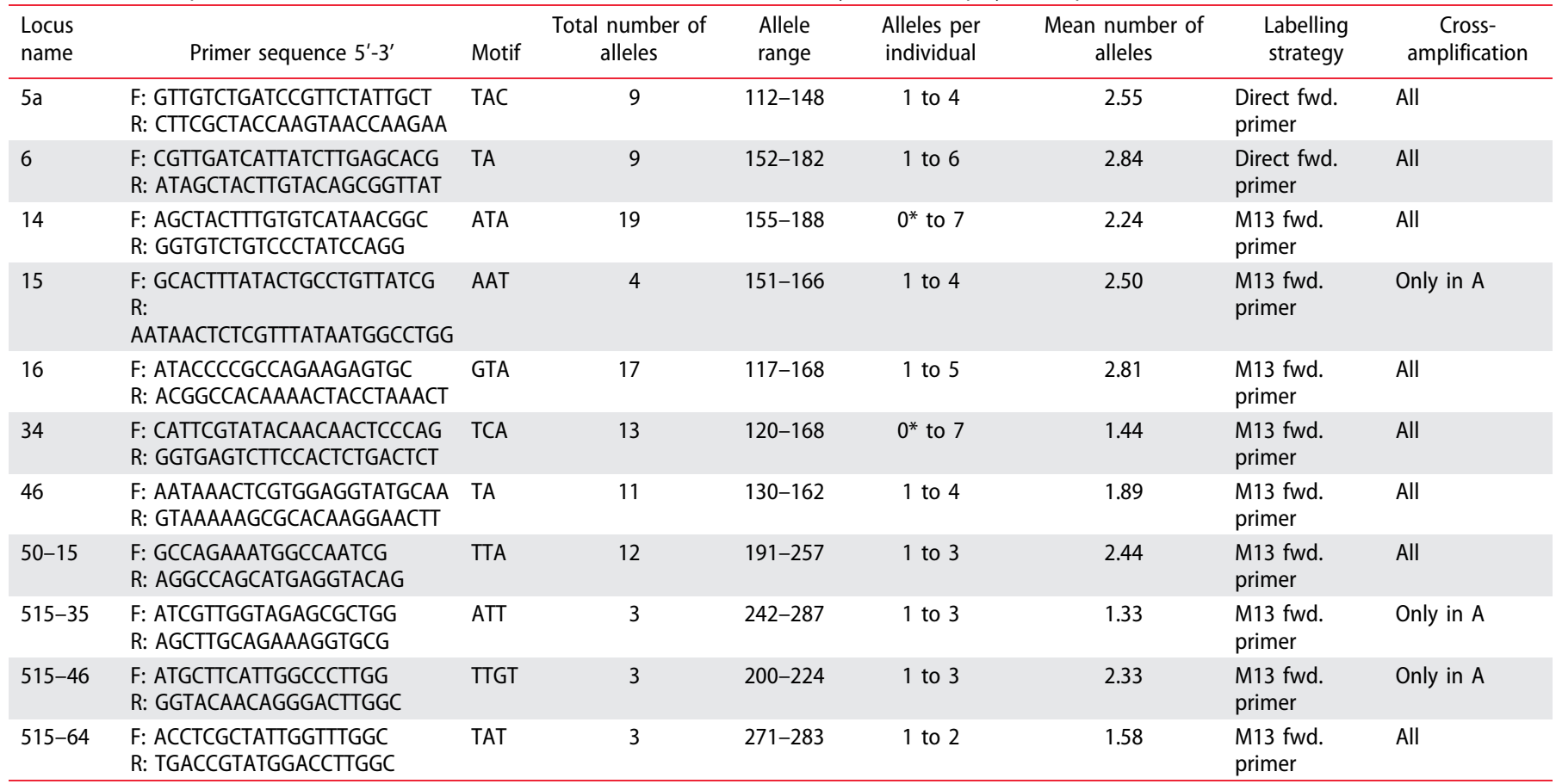

* indicates the presence of potential null alleles. 


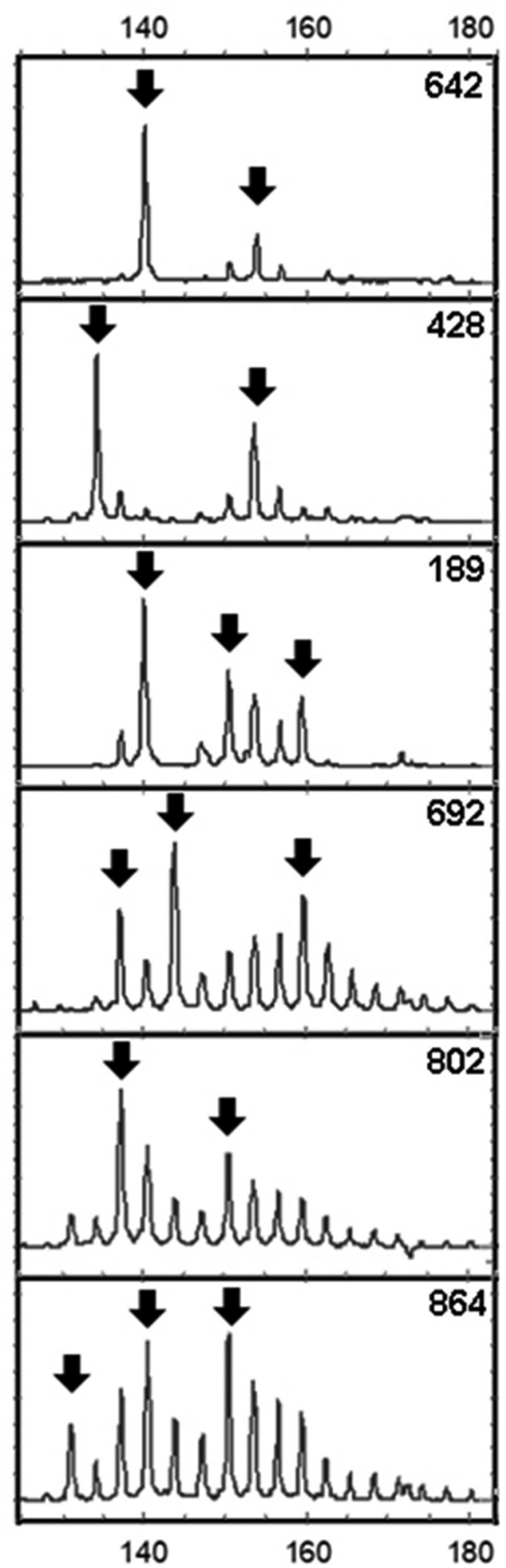

Fig 1. Chromatograms of locus 5a showing alleles scored. Arrows indicate alleles, based on peak height and position. Numbers as sample number for different morphospecies (Table S1).

\section{Microsatellite diversity}

The scoring revealed consistent patterns of multiple alleles per locus per individual, indicative of polyploidy (Figs 1,2). All loci except for locus 515-64 had more than two alleles (Table 2).

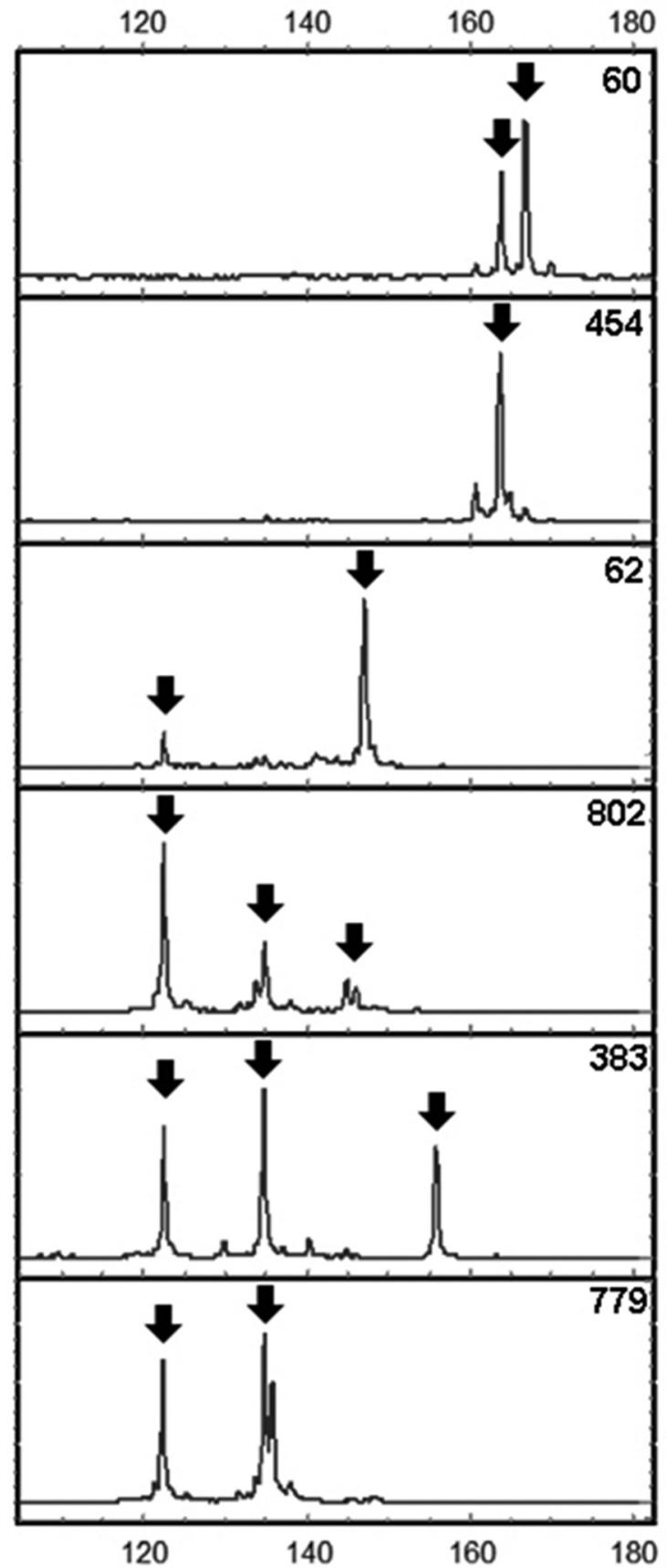

Fig 2. Chromatograms of locus 16 showing alleles scored. Arrows indicate alleles, based on peak height and position. Numbers as sample number for different morphospecies (Table S1).

Number of alleles per individual was up to seven in loci 14 and 34. Total number of alleles found in all 11 loci combined was 103 where the total number of alleles for each morphospecies ranged from 19 to 37 (Table 3). The unbiased diversity value $(u h)$ had a mean value of 0.136 , and a total of 30 private alleles $\mathrm{Pa}$ ) were detected (Table 3 ). All samples had a unique genotype differing in at least one allele. It is worth noting that chromatogram profiles of some loci were identical in samples of the same morphospecies, and that fragments amplified with proof-reading polymerase did not show significant differences from those obtained with the standard Taq polymerase. Therefore, these chromatograms were reproducible, and the 


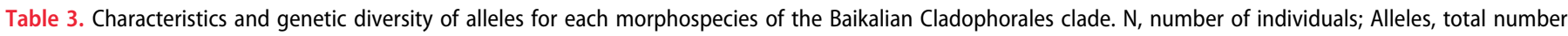
of alleles; uh, mean value of unbiased diversity; and $P a$, the number of private alleles.

\begin{tabular}{|c|c|c|c|c|}
\hline Taxa & $\mathrm{N}$ & Alleles & uh & $\mathrm{Pa}$ \\
\hline Chaetomorpha baicalensis K.I.Meyer & 3 & 27 & 0.091 & 3 \\
\hline Chaetomorpha curta (Skab.) Skabitschevsky & 3 & 30 & 0.123 & 2 \\
\hline Chaetomorpha moniliformis Skabitschevsky & 3 & 18 & 0.026 & 0 \\
\hline Cladophora compacta (K.I.Meyer) K.I.Meyer & 4 & 37 & 0.172 & 4 \\
\hline Cladophora floccosa K.I.Meyer var. floccosa & 3 & 24 & 0.097 & 0 \\
\hline Cladophora floccosa var. irregularis Skabitschevsky & 2 & 31 & 0.233 & 3 \\
\hline Cladophora globulus (C.Meyer) C.Meyer/Cladophora compacta & 2 & 36 & 0.252 & 1 \\
\hline Cladophora globulus/Cladophora pulvinata (K.I.Meyer) K.I.Meyer & 2 & 28 & 0.136 & 2 \\
\hline Cladophora kursanovii Skabitschevsky & 4 & 36 & 0.107 & 8 \\
\hline Cladophora meyeri Skabitschevsky var. meyeri & 3 & 31 & 0.175 & 4 \\
\hline Cladophora meyeri var. gracilior (Meyer) Hollerbach & 2 & 34 & 0.272 & 2 \\
\hline Cladophora pulvinata (K.I.Meyer) K.I.Meyer & 3 & 25 & 0.071 & 0 \\
\hline Gemmiphora compacta Skabitschevsky & 2 & 25 & 0.087 & 1 \\
\hline Rhizoclonium sp. & 2 & 28 & 0.068 & 0 \\
\hline Total & 38 & 103 & $0.136^{*}$ & 30 \\
\hline
\end{tabular}

* indicates mean value.

profiles obtained from both types of polymerase were considered to be equally informative.

Jaccard $(\mathrm{J})$ pairwise distances among all individuals retrieved similarity values ranging from 0.04 to 0.94 with a mean of 0.26 . The similarity tree built using this index (Fig. 3) shows the grouping of many individuals belonging to the same morphospecies: Ch. baicalensis $(\mathrm{J}=0.5)$; the attached form of Ch. curta $(\mathrm{J}=0.61)$; Cl. kursanovii $(\mathrm{J}=0.55)$; $\mathrm{Cl}$. pulvinata $(\mathrm{J}=0.67)$; . compacta $(\mathrm{J}=0.64)$; and Rhizoclonium sp. $(\mathrm{J}=0.75)$. Ch. moniliformis was included in a group with high similarity $(J=0.84)$; however, this also included a sample of the unattached form of Ch. curta 638 . The remaining individuals, with overall low levels of similarity $(\mathrm{J}<0.5)$, were not grouped in exclusive branches according to their respective morphospecies.

\section{DISCUSSION}

The HTS approach for the development of SSRs in non-model organisms allowed us to obtain a set of microsatellites that cross-amplified between morphospecies. These results showed that the markers designed displayed variation that can address evolutionary questions of these endemic algae such as their population structure and species delimitation of the morphotaxa. Microsatellites also revealed that the species flock of Baikalian Cladophoraceae consists of a clade that could be shaped by polyploidisation events and therefore needs a different approach to analyse its diversity. In addition, some preliminary insights into the partial genome of the Baikalian Cladophoraceae were obtained.

The total number of SSRs discovered from the HTS datasets differed between morphospecies. Although Ch. baicalensis and $\mathrm{Cl}$. kursanovii had a similar number of contigs, the number of SSRs in Ch. baicalensis was nearly $60 \%$ fewer (Table 1). The dominance of trinucleotide SSRs in Baikalian Cladophoraceae appears to be similar to other green algae, such as Chlamydomonas communis and Volvox reinhardtii (Zhao et al. 2014), and the brown alga Saccharina japonica
(Li et al. 2015; Zhang et al. 2016). In contrast, dinucleotide repeats are reported as dominant in the green alga Ulva prolifera (Ulvophyceae; Li et al. 2016), red algae (AyresOstrock et al. 2016; Couceiro et al. 2011), and land plants (see Schoebel et al. 2013). The reason for trinucleotide SSRs dominance in Baikalian Cladophoraceae is unclear.

The in silico cross-validation process allowed us to detect and design markers that cross-amplified among the Baikalian Cladophoraceae, either in all morphospecies or in species of group A (56 combined). However, only 11 were selected for the final tests, as many were not polymorphic. The number of non-polymorphic markers (23) and the high proportion of primers that produced amplicons between Baikalian Cladophoraceae species may result from low genetic variation between these species, in spite of their morphological differences, possibly due to a recent radiation as has been suggested (Boedeker et al. 2018).

The results provided an overview of genetic differentiation and diversity in morphospecies. The UPGMA tree (Fig. 3) often grouped morphospecies, indicating that the scoring methodologies are useful in delimiting species. Unbiased diversity values (Table 3 ) also differed between each morphospecies. However, these results should not be considered conclusive until more data are gathered and more individuals per species and per population are included.

The number of alleles per locus indicates that polyploidy occurs in this group. Although this could be attributed to duplicated loci across the genome, the occurrence of more than two alleles in different loci indicates that polyploidy is most likely, as observed in other algal studies (Andreakis et al. 2009; Varela-Álvarez et al. 2017ba, b). Contamination of multiple individuals in DNA extracts could also be discarded as some loci with more than two alleles occurred in extractions where clearly a single filament was used, such as in individuals of Chaetomorpha. In addition, the occurrence of repeated profiles in different samples of the same species suggests that random amplifications of fragments are also unlikely. Karyological and flow cytometry studies using fresh 


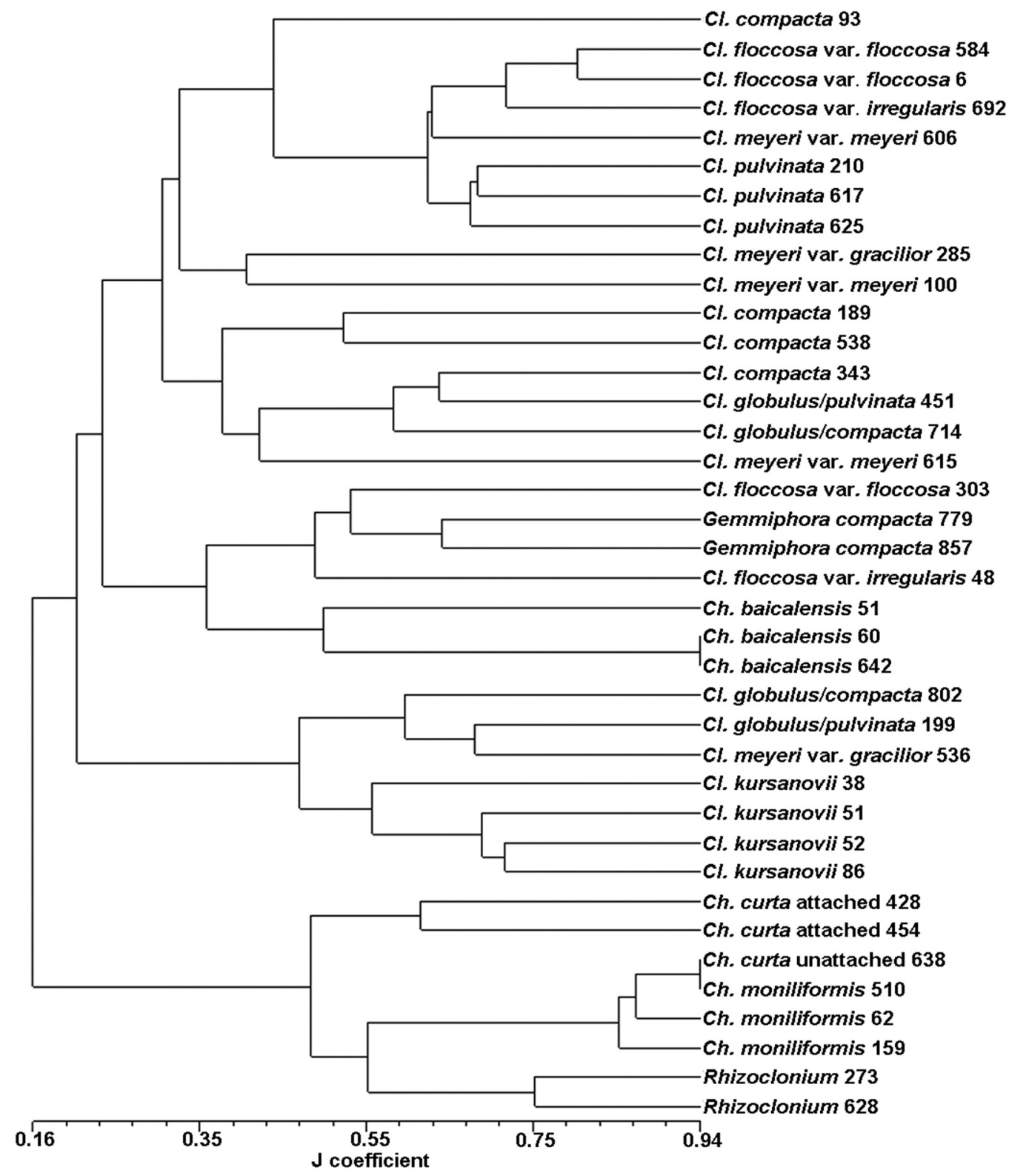

Fig 3. UPGMA tree based on the Jaccard similarity coefficient from allelic phenotypes of 11 loci. See Table S1 for taxon names.

or cultured samples may contribute to confirm the ploidy levels.

Polyploidy complicates the use of standard statistics for population genetic analysis (e.g. $\mathrm{F}_{\mathrm{st}}$, expected heterozygosity). In cases of low ploidy levels, such as in tetraploids, it is possible to determine allelic dosage using peak ratios of chromatograms (Esselink et al. 2004) or by computational algorithms (e.g. Clark \& Jasieniuk 2011; Van Puyvelde et al. 2010). However, these methods require previous knowledge of sample ploidy level (i.e. chromosome counts or total DNA content per nucleus) and knowledge of whether polyploidy is due to alloploidy (product of hybridisation between different species) or autoploidy (genome doubling), in order to sort allele dosage correctly (Dufresne et al. 2014).

Coding the SSRs as dominant data in 'allelic phenotypes' is a simple way for dealing with polyploids, as no complex assumptions are made about the data (Cidade et al. 2013) and have the advantage of allowing the inclusion of organisms with different ploidy level in the same dataset. Although this reduces the potential informative power of SSRs, it is a convenient solution when the ploidy number is unknown and when the sorting of alleles cannot be resolved (García-Verdugo et al. 2013; Obbard et al. 2006; Pfeiffer et al. 2011). In addition, some other properties of the population such as the total number of alleles and number of private alleles within populations are not affected (López-Vinyallonga et al. 2015). This approach proved to be informative for Baikalian Cladophoraceae as our analyses showed diversity within the microsatellite markers, and the number of private alleles confirms that these markers have enough power to discriminate between most morphospecies regardless of the unknown ploidy level. Likewise, the J-similarity tree, which considers all genotypes independently, retrieved clusters that in many cases were consistent with morphospecies (e.g. Cl. curta, Cl. kursanovii, Cl. pulvinata, Ch. 
baicalensis, and Ch. moniliformis). These results are similar to phylogenetic trees based on ribosomal markers (Boedeker et al. 2018). However, broader sampling and a more in-depth analysis are required to perform proper species delimitation and test for reproductive isolation of species.

Polyploidy could be playing an important role in the evolution of the Baikalian Cladophoraceae species flock. Polyploid speciation occurs when the progeny is reproductively isolated from their parents ('instant speciation'; Albert \& Schluter 2005; Schluter 2001). Furthermore, polyploidy often results in phenotypic changes and life cycle modifications in plants (Comai 2005; Soltis et al. 2010). Therefore, this process could explain some of the wide morphological diversity found in this group.

In conclusion, the HTS data combined with the in silico cross-validation procedure allowed us to explore the genome of these taxa and design a set of cross-amplifying SSRs to study population genetics and reproductive isolation of this mostly endemic Baikalian Cladophoraceae, a group recently discovered to represent a species flock. The markers designed here proved to be promising for studying reproductive isolation and genetic differentiation, as information was sufficient to cluster several morphospecies. Finally, our data revealed evidence for polyploidy, a process that could have shaped the evolution of this group.

\section{ACKNOWLEDGEMENTS}

O. A. Timoshkin, A. Kupchinsky, and the crews of the research vessels Titov, Papanin, and Koptyug (Limnological Institute of the Russian Academy of Sciences, Irkutsk) as well as S. Ihnken are thanked for their assistance with fieldwork. Finally, we thank Editor David Garbary and two anonymous reviewers for their critical comments and corrections.

\section{FUNDING}

We thank the Royal Society of New Zealand (Marsden Fund FastStart) for the funds provided for this research. S.D.-M thanks Victoria University of Wellington for a Doctoral Scholarship.

\section{ORCID}

Sergio Díaz Martínez (D) http://orcid.org/0000-0002-9164-5976 Christian Boedeker (D) http://orcid.org/0000-0001-5230-4581

Giuseppe C. Zuccarello (D) http://orcid.org/0000-0003-0028-7227

\section{REFERENCES}

Albert A.Y.K. \& Schluter D. 2005. Selection and the origin of species. Current Biology 15: R283-R288. DOI: 10.1016/j.cub.2005.04.015.

Andreakis N., Kooistra W.H.C.F. \& Procaccini G. 2009. High genetic diversity and connectivity in the polyploid invasive seaweed Asparagopsis taxiformis (Bonnemaisoniales) in the Mediterranean, explored with microsatellite alleles and multilocus genotypes. Molecular Ecology 18: 212-226. DOI: 10.1111/j.1365294X.2008.04022.x.

Ayres-Ostrock L.M., Mauger S., Plastino E.M., Oliveira M.C., Valero M. \& Destombe C. 2016. Development and characterization of microsatellite markers in two agarophyte species, Gracilaria birdiae and Gracilaria caudata (Gracilariaceae, Rhodophyta), using next-generation sequencing. Journal of Applied Phycology 28: 653-662. DOI: 10.1007/ s10811-015-0592-7.

Besnard G., Garcia-Verdugo C., Rubio De Casas R., Treier U.A., Galland N. \& Vargas P. 2008. Polyploidy in the olive complex (Olea europaea): evidence from flow cytometry and nuclear microsatellite analyses. Annals of Botany 101: 25-30. DOI: 10.1093/aob/mcm 275 .

Bhandawat A., Singh G., Raina A.S., Kaur J. \& Sharma R.K. 2016. Development of genic SSR marker resource from RNA-Seq data in Dendrocalamus latiflorus. Journal of Plant Biochemistry and Biotechnology 25: 179-190. DOI: 10.1007/s13562-015-0323-9.

Boedeker C., Leliaert F., Timoshkin O.A., Vishnyakov V.S., DíazMartínez S. \& Zuccarello G.C. 2018. The endemic Cladophorales (Ulvophyceae) of ancient Lake Baikal represent a monophyletic group of very closely related but morphologically diverse species. Journal of Phycology 54: 616-629. DOI: 10.1111/jpy.12773.

Boedeker C., Leliaert F. \& Zuccarello G.C. 2016. Molecular phylogeny of the Cladophoraceae (Cladophorales, Ulvophyceae), with the resurrection of Acrocladus Nägeli and Willeella Børgesen, and the description of Lurbica gen. nov. and Pseudorhizoclonium gen. nov. Journal of Phycology 52: 905-928. DOI: doi.10.1111/jpy.12457.

Boedeker C., O'Kelly C.J., Star W. \& Leliaert F. 2012. Molecular phylogeny and taxonomy of the Aegagropila clade (Cladophorales, Ulvophyceae), including the description of Aegagropilopsis gen. nov. and Pseudocladophora gen. nov. Journal of Phycology 48: 808-825. DOI: $10.1111 /$ j.1529-8817.2012.01145.x.

Cărăbuș M.C., Leinemann L., Curtu A.L. \& Şofletea N. 2015. Preliminary results on the genetic diversity of Carpinus belutus in carpathian populations. Bulletin of the Transilvania University of Brasov. Forestry, Wood Industry, Agricultural Food Engineering. Series II 8: $1-6$.

Cidade F.W., Vigna B.B., de Souza F.H., Valls J.F.M., Dall'Agnol M., Zucchi M.I., de Souza-chies T.T. \& Souza A.P. 2013. Genetic variation in polyploid forage grass: assessing the molecular genetic variability in the Paspalum genus. BMC Genetics 14: 50. DOI: 10.1186/1471-215614-50.

Clark L.V. \& Jasieniuk M. 2011. POLYSAT: an R package for polyploid microsatellite analysis. Molecular Ecology Resources 11: 562-566. DOI: 10.1111/j.1755-0998.2011.02985.x.

Comai L. 2005. The advantages and disadvantages of being polyploid. Nature Reviews Genetics 6: 836-846. DOI: 10.1038/nrg1711.

Couceiro L., Le Gac M., Hunsperger H.M., Mauger S., Destombe C., Cock J.M., Ahmed S., Coelho S.M., Valero M. \& Peters A.F. 2015. Evolution and maintenance of haploid - diploid life cycles in natural populations: the case of the marine brown alga Ectocarpus. Evolution 69: 1808-1822. DOI: 10.1111/evo.12702.

Couceiro L., Maneiro I., Mauger S., Valero M., Ruiz J.M. \& Barreiro R. 2011. Microsatellite development in Rhodophyta using high-throughput sequence data. Journal of Phycology 47: 1258-1265. DOI: $10.1111 /$ j.1529-8817.2011.01075.x.

Cristescu M.E., Adamowicz S.J., Vaillant J.J. \& Haffner D.G. 2010. Ancient lakes revisited: from the ecology to the genetics of speciation. Molecular Ecology 19: 4837-4851. DOI: 10.1111/j.1365294X.2010.04832.x.

Dufresne F., Stift M., Vergilino R. \& Mable B.K. 2014. Recent progress and challenges in population genetics of polyploid organisms: an overview of current state-of-the-art molecular and statistical tools. Molecular Ecology 23: 40-69. DOI: 10.1111/mec.12581.

Engel C.R., Destombe C. \& Valero M. 2004. Mating system and gene flow in the red seaweed Gracilaria gracilis: effect of haploid-diploid life history and intertidal rocky shore landscape on fine-scale genetic structure. Heredity 92: 289-298. DOI: 10.1038/sj.hdy.6800407.

Esselink G.D., Nybom H. \& Vosman B. 2004. Assignment of allelic configuration in polyploids using the MAC-PR (microsatellite DNA allele counting - peak ratios) method. Theoretical and Applied Genetics 109: 402-408. DOI: 10.1007/s00122-004-1645-5.

Faircloth B. 2008. MSATCOMMANDER: detection of microsatellite repeat arrays and automated, locus-specific primer design. Molecular Ecology Resources 8: 92-94. DOI: 10.1111/j.1471-8286.2007.01884.x. 
García-Verdugo C., Calleja J.A., Vargas P., Silva L., Moreira O. \& Pulido F. 2013. Polyploidy and microsatellite variation in the relict tree Prunus lusitanica L.: how effective are refugia in preserving genotypic diversity of clonal taxa? Molecular Ecology 22: 1546-1557. DOI: $10.1111 / \mathrm{mec} .12194$.

Gardner M.G., Fitch A.J., Bertozzi T. \& Lowe A.J. 2011. Rise of the machines - recommendations for ecologists when using next generation sequencing for microsatellite development. Molecular Ecology Resources 11: 1093-1101. DOI: 10.1111/j.1755-0998.2011.03037.x.

Goff L. \& Moon D. 1993. PCR amplification of nuclear and plastid genes from algal herbarium specimens and algal spores. Journal of Phycology 29: 381-384. DOI: 10.1111/j.0022-3646.1993.00381.x.

Graham L.E. 1982. Cytology, ultrastructure, taxonomy, and phylogenetic relationships of Great Lakes filamentous algae. Journal of Great Lakes Research 8: 3-9. DOI: 10.1016/S0380-1330(82)71935-5.

Greenwood P.H. 1984. What is a species flock? In: Evolution of fish species flocks (Ed. by A.A. Echelle \& I. Kornfield), pp. 13-19. University of Maine, Orono Press, Maine, USA. 257 pp

Guichoux E., Lagache L., Wagner S., Chaumeil P., Léger P., Lepais O., Lepoittevin C., Malausa T., Revardel E., Salin F. et al. 2011. Current trends in microsatellite genotyping. Molecular Ecology Resources 11: 591-611. DOI: 10.1111/j.1755-0998.2011.03014.x.

Guillemin M.L., Faugeron S., Destombe C., Viard F., Correa J.A. \& Valero M. 2008. Genetic variation in wild and cultivated populations of the haploid-diploid red alga Gracilaria chilensis: how farming practices favor asexual reproduction and heterozygosity. Evolution 62: 1500-1519. DOI: 10.1111/j.1558-5646.2008.00373.x.

Hanyuda T., Wakana I., Arai S., Miyaji K., Watano Y. \& Ueda K. 2002. Phylogenetic relationships within Cladophorales (Ulvophyceae, Chlorophyta) inferred from 18s rRNA gene sequences, with special reference to Aegagropila linnaei. Journal of Phycology 38: 564-571. DOI: 10.1046/j.1529-8817.2002.01151.x.

Henrichs D.W., Renshaw M.A., Gold J.R. \& Campbell L. 2013. Genetic diversity among clonal isolates of Karenia brevis as measured with microsatellite markers. Harmful Algae 21-22: 30-35. DOI: 10.1016/j. hal.2012.11.003.

Hinson T.K. \& Kapraun D.F. 1991. Karyology and nuclear DNA quantification of four species of Chaetomorpha (Cladophorales, Chlorophyta) from the western Atlantic. Helgoland Marine Research 45: 273-285. DOI: $10.1007 / \mathrm{bf} 02365520$.

Izhboldina L. 2007. Guide and key to benthonic and periphyton algae of Lake Baikal (meio- and macrophytes) with short notes of their ecology. Nauka-Tsentr, Novosibirsk, Russia. 248 pp.

Kapraun D.F. 2007. Nuclear DNA content estimates in green algal lineages: Chlorophyta and Streptophyta. Annals of Botany 99: 677-701. DOI: 10.1093/aob/mcl294.

Kapraun D.F., Braly K.S. \& Freshwater D.W. 2007. Nuclear DNA content variation in the freshwater red algal orders Batrachospermales and Thoreales (Florideophyceae, Nemaliophycidae). Phycologia 46: 54-62. DOI: $10.2216 / 06-18.1$.

Kearse M., Moir R., Wilson A., Stones-Havas S., Cheung M., Sturrock S., Buxton S., Cooper A., Markowitz S., Duran C. et al. 2012. Geneious basic: an integrated and extendable desktop software platform for the organization and analysis of sequence data. Bioinformatics (Oxford, England) 28: 1647-1649. DOI: 10.1093/bioinformatics/bts199.

Könyves K., David J.C. \& Culham A. 2016. Microsatellite markers for hoop-petticoat daffodils (Narcissus sect. Bulbocodii; Amaryllidaceae). Applications in Plant Sciences 4: 1500127. DOI: 10.3732/apps.1500127.

Kostamo K., Korpelainen H. \& Olsson S. 2012. Comparative study on the population genetics of the red algae Furcellaria lumbricalis occupying different salinity conditions. Marine Biology 159: 561-571. DOI: 10.1007/s00227-011-1835-z.

Krueger-Hadfield S.A., Collén J., Daguin-Thiébaut C. \& Valero M. 2011. Genetic population structure and mating system in Chondrus crispus (Rhodophyta). Journal of Phycology 47: 440-450. DOI: 10.1111/j.15298817.2011.00995.x.

Krueger-Hadfield S.A., Kollars N.M., Byers J.E., Greig T.W., Hammann M., Murray D.C., Murren C.J., Strand A.E., Terada R., Weinberger F. et al. 2016. Invasion of novel habitats uncouples haplo-diplontic life cycles. Molecular Ecology 25: 3801-3816. DOI: 10.1111/mec.13718.

Krueger-Hadfield S.A., Kollars N.M., Strand A.E., Byers J.E., Shainker S. J., Terada R., Greig T.W., Hammann M., Murray D.C. \& Sotka E.E. 2017. Genetic identification of source and likely vector of a widespread marine invader. Ecology and Evolution 7: 4432-4447. DOI: $10.1002 /$ ece3.3001.

Kulikovskiy M.S., Lange-Bertalot H., Metzeltin D. \& Witkowski A. 2012. Lake Baikal: hotspot of endemic diatoms. Iconographia Diatomologica 23: $1-601$.

Li Q., Zhang J., Yao J., Wang X. \& Duan D. 2015. Development of Saccharina japonica genomic SSR markers using next-generation sequencing. Journal of Applied Phycology 28: 1387-1390. DOI: 10.1007/s10811-015-0643-0.

Li Y., Huang H.-J., Li H., Liu J. \& Yang W. 2016. Genetic diversity of Ulva prolifera population in Qingdao coastal water during the green algal blooms revealed by microsatellite. Marine Pollution Bulletin 111: 237-246. DOI: 10.1016/j.marpolbul.2016.07.001.

López-Vinyallonga S., Soriano I., Susanna A., Montserra J.M., Roquet C. \& Garcia-Jacas N. 2015. The polyploid series of the Achillea millefolium aggregate in the Iberian Peninsula investigated using microsatellites. PLOS One 10: 1-19. DOI: 10.1371/journal. pone.0129861.

Mats V. 1993. The structure and development of the Baikal rift depression. Earth - Science Reviews 34: 81-118. DOI: 10.1016/00128252(93)90028-6.

Montecinos A.E., Guillemin M.L., Couceiro L., Peters A.F., Stoeckel S. \& Valero M. 2017. Hybridization between two cryptic filamentous brown seaweeds along the shore: analysing pre- and postzygotic barriers in populations of individuals with varying ploidy levels. Molecular Ecology 26: 3497-3512. DOI: 10.1111/mec.14098.

Obbard D.J., Harris S.A. \& Pannell J.R. 2006. Simple allelic-phenotype diversity and differentiation statistics for allopolyploids. Heredity 97: 296-303. DOI: 10.1038/sj.hdy.6800862.

Parodi E.R. \& Cáceres E.J. 1991. Variation in number of apical ramifications and vegetative cell length in freshwater populations of Cladophora (Ulvophyceae, Chlorophyta). Journal of Phycology 27: 628-633. DOI: 10.1111/j.0022-3646.1991.00628.x.

Peakall R. \& Smouse P.E. 2012. GenAlEx 6.5: genetic analysis in Excel. Population genetic software for teaching and research - an update. Bioinformatics 28: 2537-2539. DOI: 10.1093/bioinformatics/bts460.

Pfeiffer T., Roschanski A.M., Pannell J.R., Korbecka G. \& Schnittler M. 2011. Characterization of microsatellite loci and reliable genotyping in a polyploid plant, Mercurialis perennis (Euphorbiaceae). Journal of Heredity 102: 479-488. DOI: 10.1093/jhered/esr024.

Rozen S. \& Skaletsky H.J. 2000. Primer3 on the WWW for general users and for biologist programmers. In: Bioinformatics methods and protocols: methods in molecular biology (Ed. by S. Krawetz \& S. Misener), pp. 365-386. Humana Press, Totowa, New Jersey, USA. 500 pp.

Schluter D. 2001. Ecology and the origin of species. Trends in Ecology \& Evolution 16: 372-380. DOI: 10.1016/S0169-5347(01)02198-X.

Schoebel C.N., Brodbeck S., Buehler D., Cornejo C., Gajurel J., Hartikainen H., Keller D., Leys M., Říčanová Š., Segelbacher G. et al. 2013. Lessons learned from microsatellite development for nonmodel organisms using 454 pyrosequencing. Journal of Evolutionary Biology 26: 600-611. DOI: 10.1111/jeb.12077.

Schön I. \& Martens K. 2012. Molecular analyses of ostracod flocks from Lake Baikal and Lake Tanganyika. Hydrobiologia 682: 91-110. DOI: 10.1007/s10750-011-0935-6.

Schuelke M. 2000. An economic method for the fluorescent labeling of PCR fragments. Nature Biotechnology 18: 233-234. DOI: 10.1038/ 72708 .

Selkoe K.A. \& Toonen R.J. 2006. Microsatellites for ecologists: a practical guide to using and evaluating microsatellite markers. Ecology Letters 9: 615-629. DOI: 10.1111/j.1461-0248.2006.00889.x.

Seo S., Ge J., King J. \& Budowle B. 2014. Reduction of stutter ratios in short tandem repeat loci typing of low copy number DNA samples. Forensic Science International: Genetics 8: 213-218. DOI: 10.1016/j. fsigen.2013.10.004. 
Sherbakov D.Y. 1999. Molecular phylogenetic studies on the origin of biodiversity in Lake Baikal. Trends in Ecology \& Evolution 14: 92-95. DOI: 10.1016/S0169-5347(98)01543-2.

Sjøtun K., Heesch S., Lluch J.R., Martín R.M., Garreta A., Brysting A.K. \& Coyer J.A. 2017. Unravelling the complexity of salt marsh fucus cottonii forms (Phaeophyceae, Fucales). European Journal of Phycology 52: 360-370. DOI: 10.1080/09670262.2017.1309688.

Škaloud P., Rindi F., Boedeker C. \& Leliaert F. 2018. Freshwater flora of central Europe, Vol 13: Chlorophyta: Ulvophyceae (Süßwasserflora von Mitteleuropa, Bd. 13: Chlorophyta: Ulvophyceae). Springer, Berlin, Heidelberg, Germany. 289 pp. DOI: 10.1007/978-3-662-55495-1.

Soltis D.E., Buggs R., Doyle J. \& Soltis P.S. 2010. What we still don't know about polyploidy. Taxon 59: 1387-1403. DOI: 10.1002/ tax.595006.

Valero M., Engel C., Billot C., Kloareg B. \& Destombe C. 2001. Concepts and issues of population genetics in seaweeds. Cahiers de Biologie Marine 42: 53-62.

Van den Hoek C., Mann D.G. \& Jahns H.M. 1995. Algae an introduction to phycology. Cambridge University Press, Cambridge, UK. 637 pp.

Van der Strate H.J., Boele-Bos S.A., Olsen J.L., Van de Zande L. \& Stam W.T. 2002a. Phylogeographic studies in the tropical seaweed Cladophoropsis membranacea (Chlorophyta, Ulvophyceae) reveal a cryptic species complex. Journal of Phycology 38: 572-582. DOI: 10.1046/j.1529-8817.2002.01170.x.

Van der Strate H.J., Van De Olsen J.L., Van De Zande L., Edwards K.J. \& Stam W.T. 2000. Isolation and characterization of microsatellite loci in the benthic seaweed, Cladophoropsis membranacea (Cladophorales, Chlorophyta). Molecular Ecology 9: 1442-1443. DOI: 10.1046/j.1365294X.2000.01007-6.x.

Van der Strate H.J., Van De Zande L., Stam W.T. \& Olsen J.L. 2002b. The contribution of haploids, diploids and clones to fine-scale population structure in the seaweed Cladophoropsis membranacea (Chlorophyta). Molecular Ecology 11: 329-345. DOI: 10.1046/j.1365294X.2002.01448.x.

Van der Strate H.J., Van de Zande L.V., Stam W.T., Haroun R.J. \& Olsen J.L. 2003. Within-island differentiation and betweenisland homogeneity: Non-equilibrium population structure in the seaweed Cladophoropsis membranacea (Chlorophyta) in the Canary Islands. European Journal of Phycology 38: 15-23. DOI: 10.1080/096702603 1000096218.

Van Puyvelde K., Van Geert A. \& Triest L. 2010. ATETRA, a new software program to analyse tetraploid microsatellite data: comparison with TETRA and TETRASET. Molecular Ecology Resources 10: 331-334. DOI: 10.1111/j.1755-0998.2009.02748.x.
Varela-Álvarez E., Balau A., Paulino C., Berecibar E., Pearson G. \& Serrão E. 2017a. Isolation and characterization of microsatellite markers for the red alga Porphyra umbilicalis. Plant Genetic Resources: Characterization and Utilization 16: 390-393. DOI: 10.1017/ S147926211700034X.

Varela-Álvarez E., Paulino C. \& Serrão E. 2017b. Development and characterization of twelve microsatellite markers for Porphyra linearis Greville. Genetica 145: 127-130. DOI: 10.1007/s10709-016-9941-y.

Volkova E.A., Bondarenko N.A. \& Timoshkin O.A. 2018. Morphotaxonomy, distribution and abundance of Spirogyra (Zygnematophyceae, Charophyta) in Lake Baikal, East Siberia. Phycologia 57: 298-308. DOI: 10.2216/17-69.1.

Wik-sjöstedt A. 1970. Cytogenetic investigations in Cladophora. Hereditas 66: 233-261. DOI: 10.1111/j.1601-5223.1970.tb02348.x.

Wilke T., Väinölä R. \& Riedel F. Eds. 2008. Patterns and processes of speciation in ancient lakes. Hydrobiologia 615:235. DOI: 10.1007/9781-4020-9582-5.

Yokoyama R. \& Goto A. 2005. Evolutionary history of freshwater sculpins, genus Cottus (Teleostei; Cottidae) and related taxa, as inferred from mitochondrial DNA phylogeny. Molecular Phylogenetics and Evolution 36: 654-668. DOI: 10.1016/j.ympev.2005.06.004.

Zardi G.I., Nicastro K.R., Canovas F., Ferreira Costa J., Serrão E.A., Pearson G.A. \& Ortiz-Barrientos D. 2011. Adaptive traits are maintained on steep selective gradients despite gene flow and hybridization in the intertidal zone. PLOS One 6: e19402. DOI: 10.1371/journal. pone.0019402.

Zerbino D. \& Birney E. 2008. Velvet: algorithms for de novo short read assembly using de Bruijn graphs. Genome Research 18: 821-829. DOI: 10.1101/gr.074492.107.

Zhang L., Peng J., Li X., Cui C., Sun J. \& Yang G. 2016. Characterization of genome-wide microsatellites of Saccharina japonica based on a preliminary assembly of Illumina sequencing reads. Journal of Ocean University of China 15: 523-532. DOI: 10.1007/s11802-016-2945-5.

Zhao Z., Guo C., Sutharzan S., Li P., Echt C.S., Zhang J. \& Liang C. 2014. Genome-wide analysis of tandem repeats in plants and green algae. G3: Genes, Genomes, Genetics 4: 67-78. DOI: 10.1534/g3.113.008524.

Zhu H., Zhao Z.-J., Liu X., Song H.-Y., Liu G.-X. \& Hu Z.-Y. 2018. Molecular phylogeny and morphological diversity of inland Cladophora (Cladophorales, Ulvophyceae) from China. Phycologia 57: 191-208. DOI: 10.2216/16-33.1.

Zuccarello G.C. \& Lokhorst G.M. 2005. Molecular phylogeny of the genus Tribonema (Xanthophyceae) using rbcL gene sequence data: monophyly of morphologically simple algal species. Phycologia 44: 384-392. DOI: 10.2216/0031-8884(2005)44[384:MPOTGT]2.0.CO;2. 